\title{
ERRATUM
}

Patrizia Landi · Nicole Métrich

Antonella Bertagnini · Mauro Rosi

\section{Dynamics of magma mixing and degassing recorded in plagioclase at Stromboli (Aeolian Archipelago, Italy)}

Published online: 20 May 2004

(C) Springer-Verlag 2004

\section{Contrib Mineral Petrol (2004) 147:213-227}

Figures 3 and 7 were given incorrect and are reproduced here.

The online version of the original article can be found at http:// dx.doi.org/10.1007/s00410-004-0555-5

P. Landi $(\bowtie) \cdot$ A. Bertagnini

Istituto Nazionale di Geofisica e Vulcanologia,

32 Via della Faggiola, 56126 Pisa, Italy

E-mail: landi@pi.ingv.it

Tel.: + 39-50-8311936

Fax: + 39-050-8311942

N. Métrich

Laboratoire Pierre Süe, CEA-CNRS, CE-Saclay,

91191 Gif / Yvette, France

M. Rosi

Dipartimento di Scienze della Terra, Universita' degli Studi di Pisa, Via S. Maria 53, 56126 Pisa, Italy 

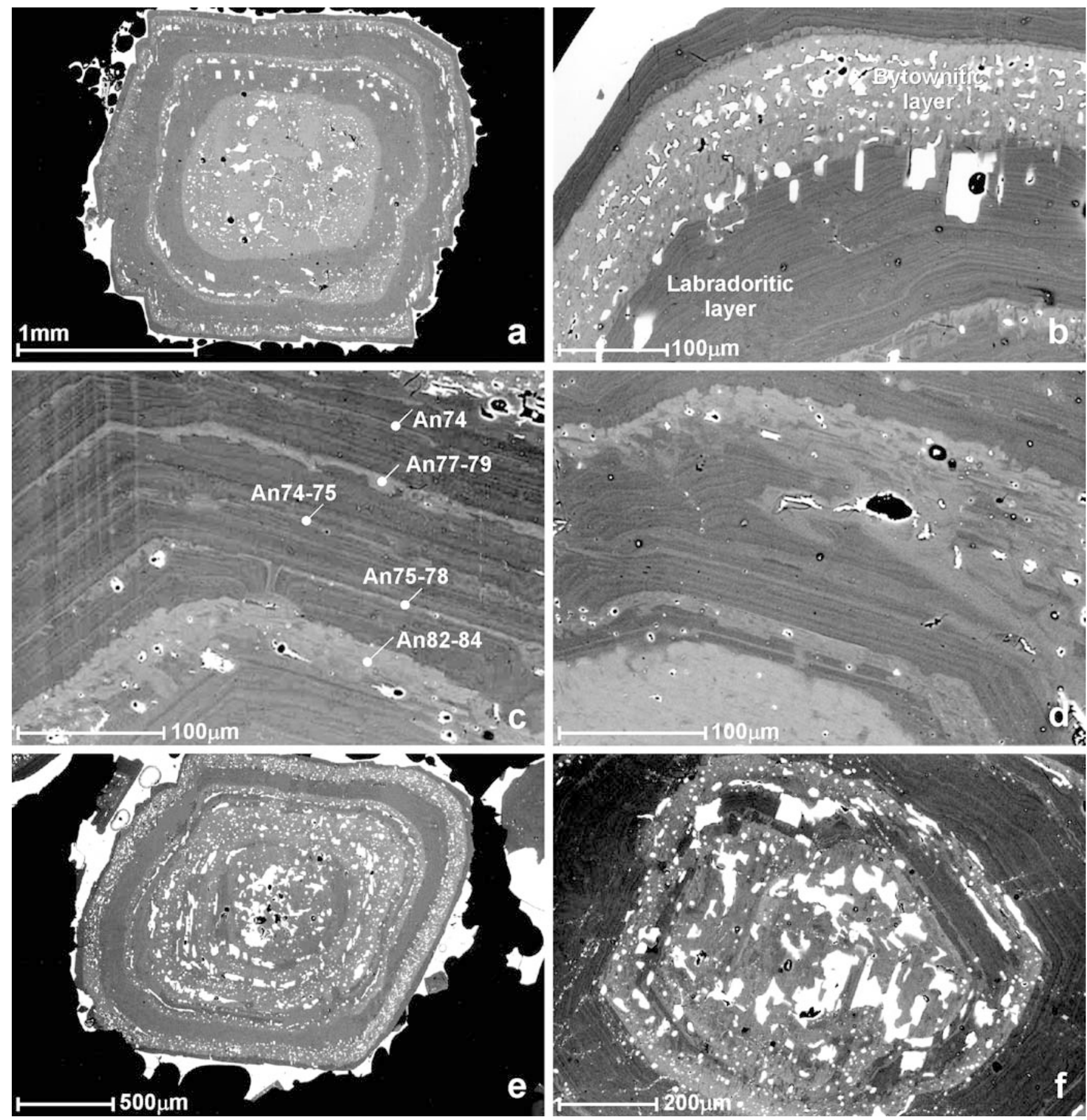
Fig. 3a-f Back-scattered electron images of plagioclase phenocrysts. Crystals are cut nearly parallel to (010) through the approximate geometric center. a) Zoned phenocryst consisting in alternating labradoritic (light gray) and bytownitic (dark gray) concentric layers. Large glass pockets are commonly present at the inner boundaries of the bytownitic layers; b) the labradoritic layers are characterized by small-scale, oscillatory zoned texture, the bytownitic by patchy-zoned, sieve textures, including micrometric glassy inclusions and voids; c) thin bytownitic layers and their compositions are shown. Thin layers have composition An74-79, whereas An contents $>80$ are typical of thick layers $(>30 \mu \mathrm{m})$; d) dissolution surfaces at the inner boundary of the bytownitic layers are marked by angular discordances and gulfs cross-cutting the labradoritic, oscillatory-zoned layers. The outer boundary are crenulate surfaces (the crystal rim is on the top) (see also b and c); e) phenocryst showing an inner part with dominant bytownitic composition and remnants of labradoritic zones resulting from partial dissolution; f) coarse sieve-textured, patchy-zoned core rimmed by relicts of labradoritic layers

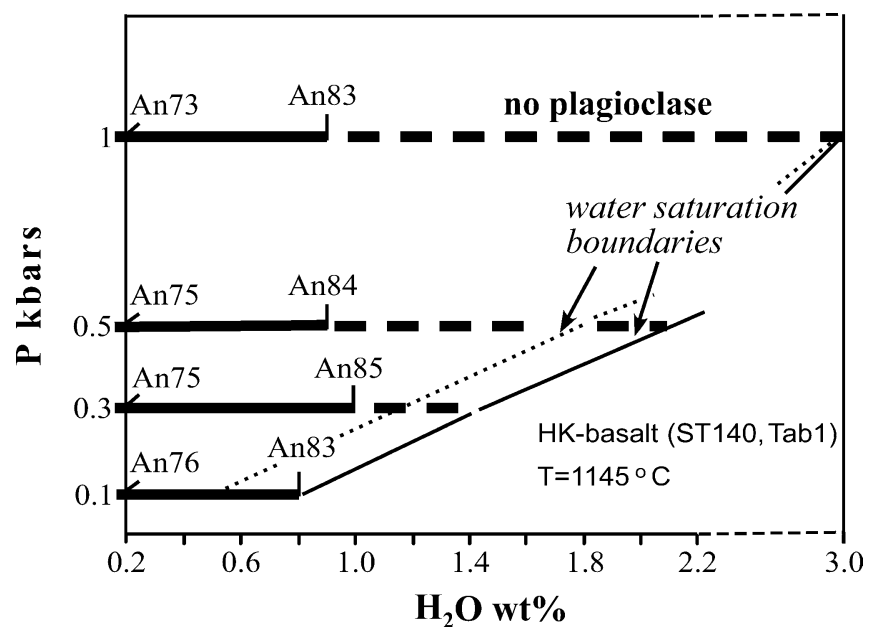

Fig. 7 Stability field of plagioclase in a HK-basaltic melt, within the range $\mathrm{H} 2 \mathrm{O} 0.2-3 \mathrm{wt} \%$ and pressure between 0.1 and $1 \mathrm{kbars}$, according to MELTS calculations (Ghiorso and Sack 1995). Water saturation boundaries according to MELTS calculations (solid line) and to Papale (1997) (dotted line) are shown 